\title{
Fish sarcoplasmic proteins as a high value marine material for wound dressing applications
}

\author{
Sara Vieira ${ }^{a, b}$, Albina R. Franco ${ }^{a, b}$, Emanuel M. Fernandes ${ }^{a, b}$, Sara Amorim ${ }^{a, b}$, \\ Helena Ferreira ${ }^{a, b}$, Ricardo A. Pires ${ }^{a, b}$, Rui L. Reis ${ }^{a, b, c}$, Albino Martins ${ }^{a, b}$, \\ Nuno M. Neves ${ }^{a, b, c, *}$ \\ a 3B's Research Group - Biomaterials, Biodegradables and Biomimetics, Headquarters of the European Institute of Excellence on Tissue Engineering and \\ Regenerative Medicine, University of Minho, Avepark 4805-017 Barco, Guimarães, Portugal \\ ${ }^{\mathrm{b}}$ ICVS/3B's - PT Government Associate Laboratory, Braga, Guimarães, Portugal \\ c The Discoveries Centre for Regenerative and Precision Medicine, Headquarters at University of Minho, Avepark 4805-017 Barco, Guimarães, Portugal
}

\section{A R T I C L E I N F O}

\section{Article history:}

Received 30 November 2017

Received in revised form 1 March 2018

Accepted 1 April 2018

Available online 5 April 2018

\section{Keywords:}

Cytocompatibility

Membranes

Physico-chemical characterization

Sarcoplasmic proteins

Spin coating

\begin{abstract}
A B S T R A C T
Fish sarcoplasmic proteins (FSP) constitute around $25-30 \%$ of the total fish muscle protein. As the FSP are water soluble, FSP were isolated from fresh cod (Gadus morhua) by centrifugation. By SDS-PAGE, it was possible to determine the composition of FSP extracts (FSP-E). The FSP-E undergo denaturation at $44.12 \pm 2.34^{\circ} \mathrm{C}$, as characterized by differential scanning calorimetry thermograms (DSC). The secondary structure of FSP-E is mainly composed by $\alpha$-helix structure, as determined by circular dichroism. The cytocompatibility of FSP-E, at concentrations ranging from 5 to $20 \mathrm{mg} / \mathrm{mL}$, was investigated. Concentrations lower than $10 \mathrm{mg} / \mathrm{mL}$ have no cytotoxicity cultures of fibroblasts over $72 \mathrm{~h}$. Further on, FSP membranes (FSP-M) were produced by spin coating to evaluate its properties. FSP-M shown having uniform surface as analyzed by Scanning Electron Microscopy (SEM). The relative amount of $\alpha$-helix structures is higher when compared with the FSP-E. The FSP-M have higher temperature stability than the FSP-E, since they presented a denaturation temperature of $58.88 \pm 3.36^{\circ} \mathrm{C}$, according to the DSC analysis. FSPM shown distinctive mechanical properties, with a stiffness of $16.57 \pm 3.95 \mathrm{MPa}$ and a yield strength of $23.85 \pm 5.97 \mathrm{MPa}$. Human lung fibroblasts cell lines (MRC-5) were cultured in direct contact with FSP-M, demonstrating its cytocompatibility for $48 \mathrm{~h}$. Based on these results, FSP can be considered a potential biomaterial recovered from nature, for wound dressing applications.
\end{abstract}

(c) 2018 Elsevier B.V. All rights reserved.

\section{Introduction}

The proteins of the fish muscle can be divided into three major classes, based on their solubility in aqueous solutions: connective tissue (stroma) proteins (3\%), myofibrillar proteins (MP) (70-80\%) or sarcoplasmic proteins (SPs) (25-30\%) [1]. The MP and the stroma proteins are water insoluble, whereas the SPs are soluble in water. Fish sarcoplasmic proteins (FSP) comprise several types of proteins, including heme proteins [2] (hemoglobin and myoglobin) and enzymes, such as creatine kinase [3], aldolase [3], glyceraldehyde-3-phosphate dehydrogenase (GAPDH) [3], phos-

\footnotetext{
* Corresponding author at: 3B's Research Group - Biomaterials, Biodegradables and Biomimetics, Headquarters of the European Institute of Excellence on Tissue Engineering and Regenerative Medicine, University of Minho, Avepark 4805-017 Barco, Guimarães, Portugal.

E-mail address: nuno@dep.uminho.pt (N.M. Neves).
}

phorylase [4], proteinase inhibitors [5], proteases A and C [6], phospholipase [7], peroxidase [8], transglutaminase (TGase) [9], fructose-bisphosphate aldolase A [10], glycogen phosphorylase [10], beta-enolase [10], triosephosphate isomerase B [10], phosphoglucomutase [10], phosphoglycerate kinase [10], parvalbumins and calmodulins [1,11].

Over the last years, fish proteins have been proposed as edible biopolymer films to protect and preserve food or as pharmaceuticals, mainly due to their advantages over synthetic polymers such as their biodegradability [12-14]. Only a few studies with FSP demonstrated the film-forming potential of those materials $[15,16]$. Sett et al. proposed a mixture of FSP from codfish (Gadus morhua) with nylon 6 as a substitute of traditional synthetic polymers [17]. In the biomedical field, Stephansen et al. developed and characterized a bioactive electrospun nano/micro-fiber mesh based on FSP from codfish [18], proposing the system for the gastrointestinal delivery of insulin [19]. Stephansen et al. also proposed nanocomplexes obtained by the electrostatic self-assembling complexation, 
formed between SPs isolated from codfish and alginate [20]. Sahin et al. produced an electrospun nanofiber based in FSP from Atlantic bonito (sarda) and poly ( $\varepsilon$-caprolactone) as an interesting material for the encapsulation and controlled release of food ingredients [21].

Marine-origin materials are frequently proposed for many biomedical applications. As examples, collagen [22], chitin [23] and chitosan [24] were reported as candidates for the development of wound dressings. However, to the best of our knowledge, no report has previously proposed FSP for this biomedical application. In the present study, we hypothesize that the FSP from codfish (Gadus morhua) processed into membranes can be applied for wound dressing. To validate this hypothesis, FSP extracts (FSPE) were isolated and processed into FSP membranes (FSP-M), by spin coating. Both FSP-E and FSP-M were physicochemically characterized to evaluate their secondary structure, the onset of their thermal denaturation and degradation. The morphology, the surface charge density and the mechanical properties of FSP-M were all analyzed. Cytocompatibility assays with a human lung fibroblast cell line (MRC-5) were conducted both for FSP-E and FSP-M.

\section{Materials and methods}

\subsection{Materials}

Codfish (Gadus morhua) from the Norway Sea (Northeast Atlantic) was purchased from MAKRO, Braga. 1,1,1,3,3,3Hexafluoro-2-propanol (HFIP) $\geq 99 \%$ was obtained from SigmaAldrich Company, St. Louis, USA.

\subsection{FSP extraction}

FSP were extracted according to the procedure described by Stephansen et al. with some alterations [18]. The frozen codfish fillet was cut into small pieces and centrifuged at $18000 \mathrm{~g}$ for $20 \mathrm{~min}$ at $3^{\circ} \mathrm{C}$ (5810R, Eppendorf, Germany). The supernatants were dialyzed at $4{ }^{\circ} \mathrm{C}$ under stirring. The dialyzed supernatant was freeze dried (CryoDos -80 , Telstar, London) and the FSP-E were stored at $-20^{\circ} \mathrm{C}$. To ensure the reproducibility of the method, this procedure was repeated three times: two extractions from one individual, and one extraction from another codfish. This resulted in three batches of FSP.

\subsection{SDS-PAGE}

Detergent sodium dodecyl sulfate polyacrylamide gel electrophoresis (SDS-PAGE) was performed for the three batches of FSP-E to analyze their protein composition. It was used a handcast gel composed of $4 \%$ acrylamide, as stacking gel, and $9 \%$ acrylamide, as separation gel. The three batches of FSP-E at $1 \mathrm{mg} / \mathrm{mL}$ were dissolved in ultra-pure water. The protein samples and standards were prepared as follows: $6 \mu \mathrm{L}$ of each protein sample was mixed with $24 \mu \mathrm{L}$ of loading buffer (15 mM Tris- $\mathrm{HCl} \mathrm{pH} 6.8,2.5 \%$-SDS, 25\% glycerol, $0.1 \%$ bromophenol blue, $5 \%$ DTT); $5 \mu \mathrm{L}$ of protein standard were mixed with $24 \mu \mathrm{L}$ of loading buffer and $1 \mu \mathrm{L}$ of ultra-pure water; as blank, $24 \mu \mathrm{L}$ of loading buffer and $6 \mu \mathrm{L}$ of ultra-pure water were mixed for each free well. All mix samples were heated and denatured and $30 \mu \mathrm{L}$ of each sample were loaded in the gel. The gel was run with a constant voltage of $150 \mathrm{~V}$.

\subsection{Production of FSP-M by spin coating}

Spin coating (WS-650Hzb-23NPPB-UD-3, Laurell Technologies) was used to produce FSP-M as a substrate. Spin coated FSP-M were prepared from a $100 \mathrm{mg} / \mathrm{mL}$ solution of FSP dissolved in
HFIP, stirred overnight at room temperature. Solution drops ranging between 0.5 and $1.5 \mathrm{~mL}$ were dispensed in the coater of a polystyrene petri dish ( $85 \mathrm{~mm}$ diameter), previously placed on the stage of a spin coater. The substrate was then spun at $1000 \mathrm{rpm}$ for $5 \mathrm{~s}$. The FSP-M were dried at room temperature in the fume hood for $48 \mathrm{~h}$. Then, they were detached and stored at room temperature until further characterization. For each batch of FSP-E, it was produced one batch of FSP-M.

\subsection{Scanning electron microscopy}

The analysis of FSP-M surface was conducted by scanning electron microscopy (SEM) (JSM-6010 LV, Jeol, Japan). The FSP-M $(10 \times 10 \mathrm{~mm})$, mounted over a stub, were sputter-coated with goldpalladium (108A, Cressington) for $1 \mathrm{~min}$ at $15 \mathrm{~mA}$. The micrographs were obtained at $10 \mathrm{kV}$ with magnifications ranging from 100 to 5000 times.

\subsection{Atomic force microscopy}

The analysis of the surface topography of the FSP-M was performed by atomic force microscopy (AFM). For this, AFM Dimension Icon (Bruker, USA) was used in PeakForce Tapping (ScanAsyst) in air. AFM cantilevers (ScanAsyst-Air, Bruker) made of silicon nitride with a spring constant of $0.4 \mathrm{~N} / \mathrm{m}$ and frequency of $70 \mathrm{kHz}$ were used.

\subsection{Water contact angle}

The water contact angle of FSP-M was determined at room temperature by a goniometer (OCA 15PLUS, DataPhysics). Contact angles were measured in the center and in the extremities, as well as on the top and the bottom surfaces of the FSP-M. Three independent membranes (each from each FSP batch) were used. $1 \mu \mathrm{L}$ of ultra-pure water was applied by a controllable syringe at a rate of $3 \mu \mathrm{L} / \mathrm{s}$ at three distinct points of each membrane and the measurement was performed. The presented data are average values of those measurements.

\subsection{Circular dichroism spectroscopy}

Circular dichroism (CD) spectra (185-260 nm) of the FSP-E and FSP-M from all batches were recorded on a CD spectrometer (J1500, JASCO, Tokio, Japan), at room temperature. Each FSP-E was dissolved in water and HFIP at a concentration of $0.1 \mathrm{mg} / \mathrm{mL}$. The solvents were used as control. A quartz cell of $1 \mathrm{~mm}$ was used for spectral measurements of FSP solution. FSP-M were analyzed between two quartz cover slip. Empty cover slips were used as control. Each spectrum was recorded in far-UV (190-260 nm) and represented as an average of three consecutive scans measured at $1 \mathrm{~nm}$ resolution.

\subsection{Differential scanning calorimetry}

The thermal stability and structural integrity of FSP-E and FSP$M$ were studied by differential scanning calorimetry (DSC) (Q100, TA Instruments). Samples were weighed and sealed into aluminum pans. An empty pan was used as reference. Samples were scanned from 0 to $150^{\circ} \mathrm{C}$, at a constant heating rate of $2^{\circ} \mathrm{C} / \mathrm{min}$. DSC scans were performed two times for each sample, named first and second runs, to check the reversibility of the unfolding transition. Each batch, for both FSP-E and FSP-M, was run. Data presented is an average value of the thermal unfolding transition temperatures. 


\subsection{Tensile tests}

To evaluate the mechanical properties of FSP-M a tensile test was performed. Ten rectangular specimens $(30 \times 6 \mathrm{~mm})$ were cut from three FSP-M. The thickness of each specimen was measured at three distinct points with a micrometer (Mitutoyo, Japan). A universal mechanical testing equipment (Model 5543, INSTRON, UK) equipped with a $1 \mathrm{kN}$ load cell was used. The strain rate was defined at $1 \mathrm{~mm} / \mathrm{min}$ and a $12 \mathrm{~mm}$ gauge length was used in the tensile tests. The tests were ended when the specimens fractured. The values reported are the average of at least twenty specimens, being shown 3 representative curves of each batch of FSP-M.

\subsection{Swelling and degradation tests}

The swelling and degradation behavior of the FSP-M were assessed according to Pinho et al. with minor modifications [25]. FSP-M were cut $(20 \times 20 \mathrm{~mm})$ to perform swelling behavior studies. Briefly, the FSP-M were first weighed (Winitial) and sterilized by UV irradiation. Then, sterilized structures were immersed in Dulbecco's modified eagle's medium (DMEM) at $37^{\circ} \mathrm{C}$. At various time points $(12,24,36,48,60$ and $72 \mathrm{~h})$, six FSP-M were removed from the DMEM, blotted with gauze for removal of the excess of DMEM, and weighed again (Wsample). Therefore, this experiment provided information about volume variation with time, i.e. the swelling rate $(S)$, which was calculated through the following Eq. (1):

Swelling $(\%)=(($ Wsample - Winitial $) /$ Winitial $) \times 100$

To evaluate the weight loss of FSP-M in close to physiological conditions, the six membranes from each time point were removed from DMEM and put at $37^{\circ} \mathrm{C}$ for $24 \mathrm{~h}$ and then weighed again (Wsample dried). This test provided information about the integrity of FSP-M immersed in DMEM with time, which was calculated according to Eq. (2):

Weight loss $(\%)=(($ Winitiall - Wsample dried $) /$ Winitial $) \times 100$

\subsection{Cytocompatibility assays}

Human lung fibroblasts (MRC-5 cell line) were grown in DMEM supplemented with $10 \%$ fetal bovine serum (FBS) and $1 \%$ antibiotic/antimycotic solution, at $37{ }^{\circ} \mathrm{C}$ in an atmosphere of $5 \% \mathrm{CO}_{2}$.

The cytotoxicity of FSP-E was determined by the extraction test [26]. The fibroblasts were seeded at a density of $5 \times 10^{4}$ cells/well in 24-wells culture plate and incubated for $24 \mathrm{~h}$ at $37^{\circ} \mathrm{C}$, in a humidified atmosphere with $5 \%$ CO2. FSP-E at different concentrations $(5-20 \mathrm{mg} / \mathrm{mL})$ were dissolved in DMEM immediately before their addition to the cells in culture. The culture medium was removed and the same volume of FSP suspension was added. The fibroblasts in culture were incubated with the different concentrations of FSP$\mathrm{E}$ for $24 \mathrm{~h}, 48 \mathrm{~h}$ and $72 \mathrm{~h}$, and cells viability determined. The negative control of cytotoxicity comprises the culture of fibroblasts just in culture medium. All conditions were performed in triplicate.

The cytotoxicity of FSP-M was determined by the direct contact method [26]. FSP-M $(10 \times 10 \mathrm{~mm})$ were sterilized by UV irradiation and placed into 24-wells culture plate. Tissue culture polystyrene (TCPS) coverslips were used as a negative control of toxicity. A cell suspension containing $5 \times 10^{4}$ cells was seeded over the FSP-M and controls. The cell viability was determined after $24 \mathrm{~h}, 48 \mathrm{~h}$ and $72 \mathrm{~h}$ of direct contact. All conditions were performed in triplicate and repeated three times.

\subsection{Cells metabolic activity}

The cell metabolic activity was determined by the dehydrogenase activity of MRC-5 cells using the MTS assay (CellTiter $96^{\circledR}$
$\mathrm{AQ}_{\text {ueous }}$ One Solution Cell Proliferation Assay, Promega). After 24, 48 and $72 \mathrm{~h}$ of culture, the medium with FSP-E or FSP-M was removed. Serum-free culture medium without phenol red and MTS reagent was added to each well at a ratio of 5:1. A FSP-M without cells immersed in DMEM was used as blank for each time point. Cells were incubated at $37^{\circ} \mathrm{C}$ for $3 \mathrm{~h}$ in a humidified atmosphere contain $5 \% \mathrm{CO}_{2}$. After, the absorbance was recorded in triplicate at $490 \mathrm{~nm}$ on a microplate reader (SYNERGY HT, BIO-TEK, USA).

\subsection{Cell morphology}

At the established times points, the medium was removed and the cells were washed with sterile PBS. After, a 2.5\% glutaraldehyde in PBS solution were added to the samples to fix the cells to the subtracts. Then, the samples were dehydrated with graded series of ethanol and let to dry overnight. MRC-5 cells submitted to FSP-E were analyzed by SEM (JSM-6010 LV, Jeol, Japan). The samples were sputter-coated with gold-palladium and the micrographs recorded at $10 \mathrm{kV}$, at magnifications ranging from 100 to 1000 times. FPS-M were observed under an inverted microscope (Axiovert 40, Zeiss).

\subsection{Statistical analysis}

Statistical analysis was performed using Graph Pad Prism Software. Differences between the different conditions of the cellular assays were analyzed using non-parametric test (Kruskal-Wallis test for FSP-E and Man-Whitney test for FSP-M assays) and a $\mathrm{p}<0.01$ was considered significant. Data were presented as mean \pm standard deviations.

\section{Results and discussion}

\subsection{Isolation of FSP-E}

FSP were extracted from codfish muscle, using fish's own water as solvent. No buffer was used in the extraction process, because it is described that when FSP are subjected to $\mathrm{pH}$ shift they unfold and expose the thiol groups [27], which subsequently affect its functional properties. In the isolation process herein conducted, the $\mathrm{pH}$ of the muscle pieces and the supernatant was monitored. The fillets and pieces presented a $\mathrm{pH}$ of $6.78 \pm 0.02$, as described in the literature $[28,29]$ and the $\mathrm{pH}$ of the supernatant was $6.61 \pm 0.02$. After dialysis, the FSP solution had a $\mathrm{pH}$ of 6.78 , which is in accordance to Iwata et al. that reported a natural $\mathrm{pH}$ of FSP solution around 6.7 [15].

\subsection{Protein composition of FSP-E}

From the SDS-PAGE analysis, it was possible to define that the protein components of FSP-E were divide into 11 bands $(12,15,25$, 35.6, 38, 40, 43, 52, 65, 98 and $110 \mathrm{kDa}$ ), as shown in Fig. 1. The dialysis process contributed to the purification of FSP-E, as demonstrated by the individualization of the bands without smearing. The bands of each FSP-E were similar, suggesting that the extraction method performed from different individuals did not affect the FSP composition. According to the literature, it can be to hypothesized the proteins that constitute the FSP-E. Enzymes such as parvalbumins (12 kDa) [1], protease A (15 kDa) [6], protease C (35.6 kDa) [6], aldolase $(40 \mathrm{kDa})[3,30]$, creatine kinase $(43 \mathrm{kDa})[3,30]$ and proteinase inhibitors ( $52 \mathrm{kDa}$ ) [5], and proteins such as hemoglobin (65 kDa) [20] can all be identified in the FSP-E. Other unidentified proteins were also observed with molecular weights around 25, 38,98 , and $110 \mathrm{kDa}$. From a literature search, FSP from catfish distinctively exhibited molecular weights of $11,13,27,31,36,38,43$, 50, 61 and $97 \mathrm{kDa}$ [30]. FSP from pacific mackerel comprised 11 proteins with molecular weights of $25,26,33,35,40,43,55,63$, 


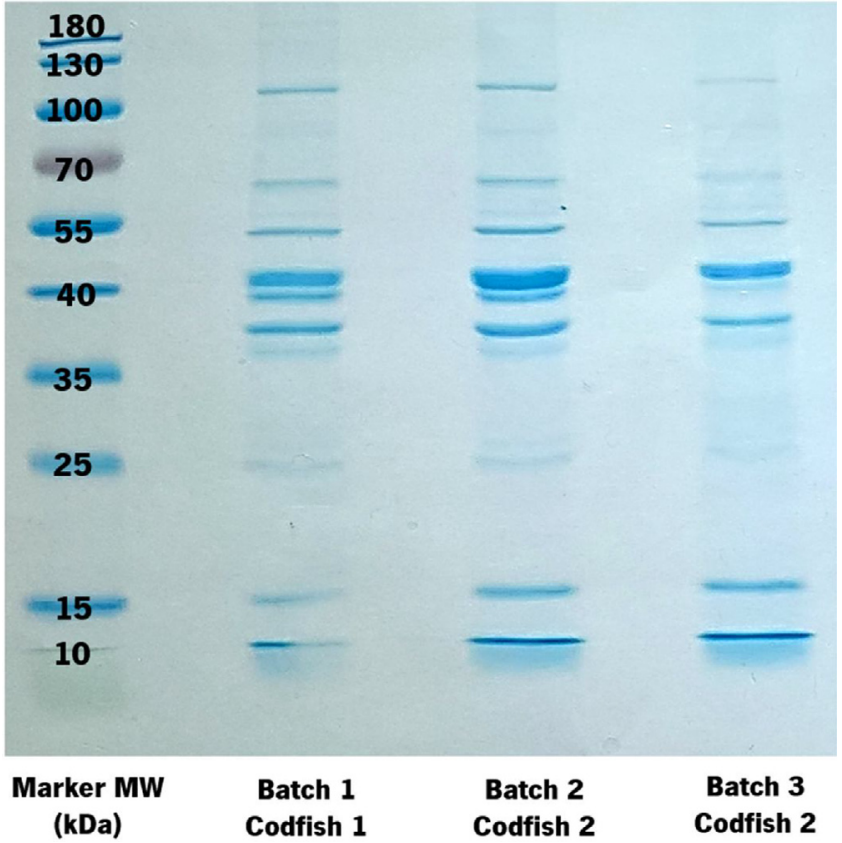

Fig. 1. SDS-PAGE showing the protein composition of FSP-E from different batches.

64,65 , and $94 \mathrm{kDa}$ [31]. Those distinctive results can be attributed to differences in the fish species and on the isolation methods. Indeed, the extraction of FSP using buffers leads to a shift in the $\mathrm{pH}$, and, consequently, to variation in FSP compositions. Proteins with molecular weights around 35-40 kDa were the most frequent ones, as described by Hemung and Chin [32]. In contrast, proteins with molecular weights of 25,38 , and $94 \mathrm{kDa}$ were present in lower amounts in the codfish samples.

Analyzing the bands pattern for each FSP-E batch it was possible to observe that, between batch 1 (codfish 1 ) and batch 2 (codfish 2) no significant differences were present. However, in batch 3 (codfish 2), the bands with 26, 40, 65 and $110 \mathrm{kDa}$ showed lower intensity, corresponding to lower amounts of those protein fractions. This fact could be related with the time that the codfish was frozen. Indeed, LeBlanc and LeBlanc analyzed the changes in FSP from frozen stored cod fillets (Gadus morhua) subjected to various storage temperatures and concluded that the frozen storage decreased the FSP content [33]. The major change observed from the different chromatograms was the loss of high molecular weight proteins, namely the bands of 110,94 and $65 \mathrm{kDa}$.

It is known that FSP are a source of different enzymes [11]. Hemoglobin was reported to promote healing of chronic wounds, for the supply of oxygen [34]. Creatine kinase is known to be important to support the high energy demands of skin cells [35]. The balance between extracellular matrix (ECM) degradation and deposition is reached by the activation of proteases and their inhibitors [36]. All these enzymes create an equilibrium contributing for an efficient wound dressing. Having this into consideration, we herein hypothesized that the FSP could have potential as biomaterial for biomedical applications, namely as wound dressings.

\subsection{Topography of FSP-M}

FSP-M were produced by spin coating and their physicochemical properties were evaluated to verify if the FSP-E change their properties when processed. A FSP-E concentration of $100 \mathrm{mg} / \mathrm{mL}$ and a volume of $1.5 \mathrm{~mL}$, it was possible to fabricate uniform and thin membranes. The average thickness, measured in 30 distinct points of three membranes, was $9.06 \pm 1.72 \mu \mathrm{m}$.
SEM micrographs of the top and bottom sides of FSP-M are presented in Fig. 2A and B, respectively. The surface profile of the top and bottom surfaces of FSP-M obtained by AFM are shown in Fig. 2C and D, respectively. As expected, the FSP-M showed a uniform surface topography, at both top and bottom sides, due to the processing technique (Fig. 2A-D). According to SEM and AFM analysis, no significant morphological differences were observed between the FSP-M produced from the different batches. This result indicates that different batches did not significantly affect the surface topography of the developed FSP-M. Pores were observed only on the top side of the FSP-M (Fig. 2A and C). These pores have an average diameter of $169.81 \pm 73.29 \mathrm{~nm}$, according to SEM micrographs (Fig. 2A). AFM analysis confirmed this parameter, since this technique shows an average pore diameter of $151.67 \pm 32.33 \mathrm{~nm}$ (Fig. 2C). The pore formation was correlated with the last stage of the membranes production, when the solvent evaporation takes place. In contrast, on the bottom side of FSP-M (Fig. 2B and D) the surface appeared smooth at the length scale analyzed, because this side was in direct contact with the polystyrene substrate.

The average surface roughness (Ra) and root mean square (RMS) roughness of the top side of the FSP-M were $2.14 \pm 0.32 \mu \mathrm{m}$ and $4.93 \pm 0.92 \mu \mathrm{m}$, respectively. The Ra and RMS parameters of the bottom side were $3.72 \pm 1.48 \mu \mathrm{m}$ and $5.18 \pm 1.79 \mu \mathrm{m}$, respectively. The top side has higher roughness, as expected, due to the presence of the pores. The bottom side also presented some roughness, although the roughness values had a higher dispersion. Considering the FSP-M surface roughness parameters, no significant statistical differences were observed between the top and bottom sides. Therefore, the cells can be seeded in both sides of FSP-M.

\subsection{Wettability of FSP-M}

Contact angle measurements for the three distinct FSP-M were performed to determine the surface properties. The contact angle mean values are shown in Fig. 3. Measurements were similar for all FSP-M, which demonstrated a water contact angle of $89.19 \pm 1.76^{\circ}$ on the top side, and $87.72 \pm 1.47^{\circ}$ on the bottom side. There are no significant differences between the top and the bottom sides of different FSP-M. The FSP-M are considered hydrophobic, since the water contact angle was close to $90^{\circ}$.

\subsection{Secondary structure of FSP-E and FSP-M}

The secondary structure of FSP-E dissolved in water and HFIP, as well as of FSP-M, was analyzed by CD spectroscopy (Fig. 4). The structure of FSP-E (dissolved in water) has a $\alpha$-helix conformation [37]. The characterized structure is composed of $\alpha$-helix conformation (45.63\%), random conformation (27.37\%), $\beta$-sheet (17\%) and $\beta$-turns (9.97\%). The $\beta$-sheet conformation has influence in the shape of the $\alpha$-helix conformation, since the negative peaks were not well defined. The dominance of the $\alpha$-helix conformation, is in agreement with the results reported by Villamonte et al. for FSP from hake [38]. The secondary structure of FSP-E was not altered by the dissolution in HFIP (53.83\% of $\alpha$-helix conformation, 37.03\% of random conformation, and $9.10 \%$ of $\beta$-turns). The differences observed in the relative intensities of the bands depend mainly on the side chains, which may be related with differences in polarity of the peptide bond environment caused by the various side-chain conformations [39].

When FSP-E dissolved in HFIP were processed into membranes, the proteins exhibited a conformational transition, leading to the formation of $100 \% \alpha$-helix structures. The proteins lost their random coil structure, since in a dried state the polypeptide chain is not able to undergo random flight structural fluctuations [39]. In this case, the CD spectrum of FSP-M did not have the characteristic shape of $\alpha$-helix conformation, which makes impossible the asso- 

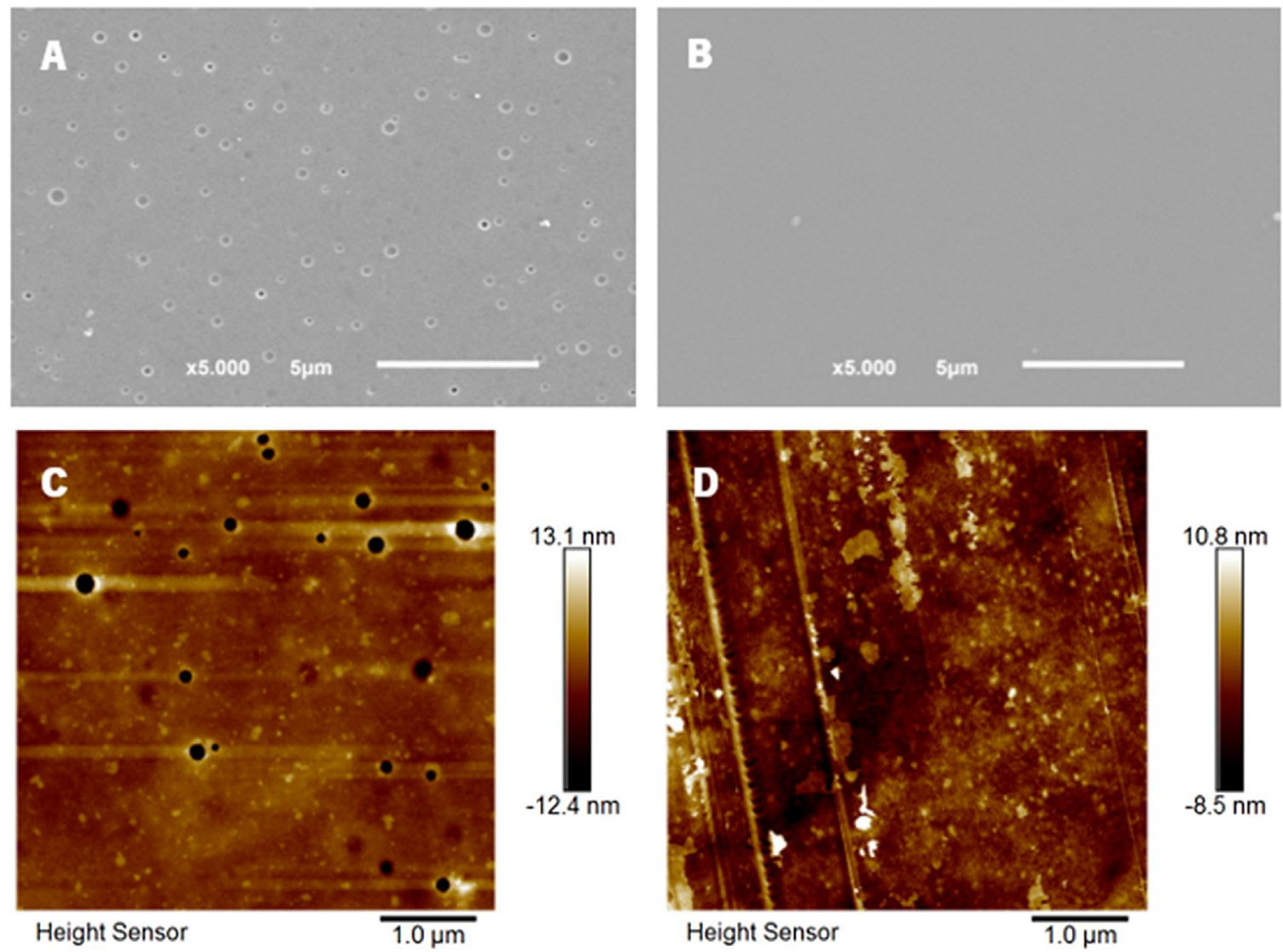

Fig. 2. SEM micrographs of FSP-M surface: (A) top and (B) bottom sides. Surface profile of top (C) and bottom (D) sides of FSP-M obtained by AFM analysis.

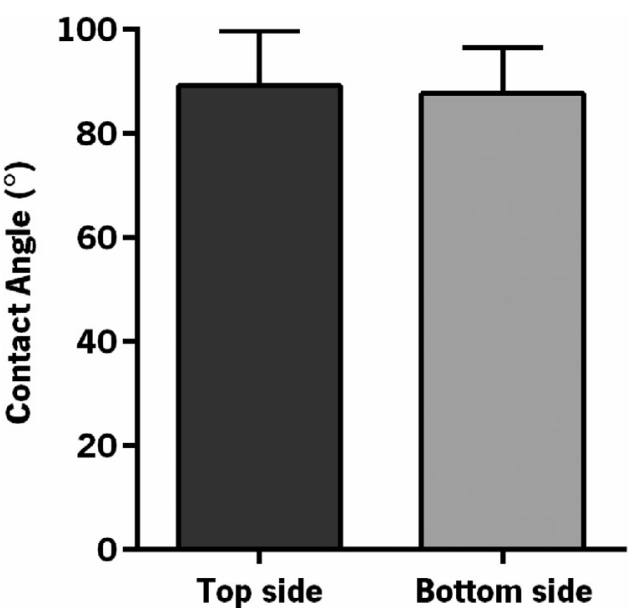

Fig. 3. Water contact angle values of FSP-M. The results were expressed as mean values and standard deviation $(n=6)$.

ciation of the spectrum to any known polypeptide conformation. Until $229 \mathrm{~nm}$, the FSP-M shows linear response, and then it becomes negative, with a peak between 254 and $231 \mathrm{~nm}$, and a minimum negative at $\approx 241 \mathrm{~nm}$. Fasman et al. described a peak at $276 \mathrm{~nm}$ in the CD spectrum of L-Tryptophan, explaining that it represents a superposition of the $\alpha$-helix bands and of the strong aromatic chromophore bands which are present in the near UV region [40]. This argument is in agreement with the applied Reed's reference, which describes a $100 \% \alpha$-helix structure. The difference between peaks can be explained by the use of HFIP as solvent. HFIP has influence on the appearance of molecular structures, which produces peak shifts, indicating a strong presence of ordered helical contents [41].

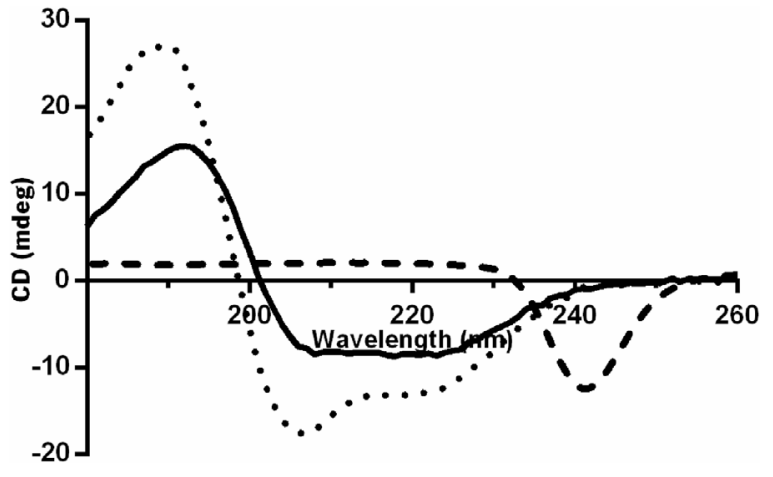

Fig. 4. CD spectrum of FSP-E dissolved in water (full line) and in HFIP (dotted line), and FSP-M (dashed line).

On the other hand, HFIP does not destroy the structure of native protein. Thus, the FSP-E after being processed change from a $\alpha$-helix conformation to an unordered structure. These changes in the secondary structure can justify the insolubility of FSP-M in DMEM and water after being processed into membranes. FTIR results (Fig. S2) confirm the previously described CD data.

\subsection{Thermal characterization of FSP-E and FSP-M}

FSP-E and FSP-M were characterized by DSC analysis (Fig. 5). The FSP-E thermogram had one defined endothermic thermal transition at approximately $44.12 \pm 2.34^{\circ} \mathrm{C}$, corresponding to the denaturation of FSP-E due to heat. All FSP batches shown similar behavior. Monterrey-Quintero and Sobral also studied the denaturation of Nile tilapia muscle proteins by DSC and determined that 


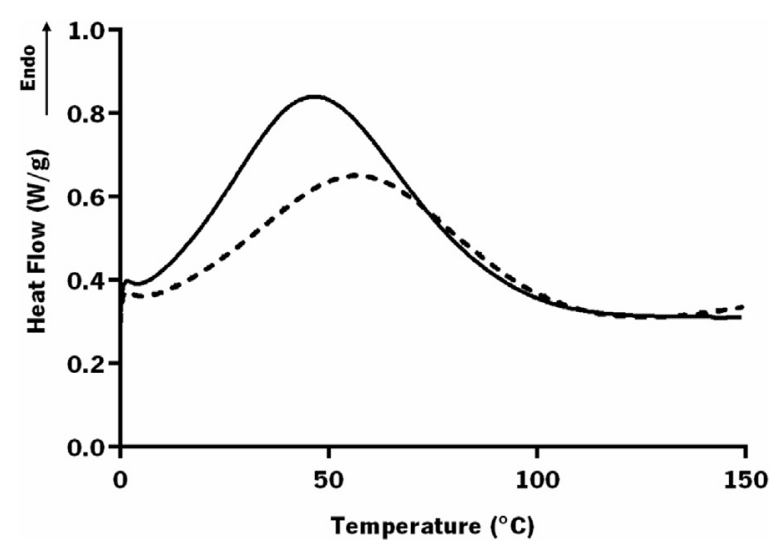

Fig. 5. DSC thermogram for FSP-E (full line) and FSP-M (dashed line).

the sarcoplasmic proteins of these fish denatured at $41.1^{\circ} \mathrm{C}$ [42]. Other denaturation temperatures of FSP can be found in the literature, varying between 42 and $45^{\circ} \mathrm{C}[28,29]$.

When the FSP-E were processed into membranes, the endothermic peak shifts into $58.88 \pm 3.36^{\circ} \mathrm{C}$. For FSP-E, the heat absorbed during the experiment was calculated to be $283.93 \pm 9.91 \mathrm{~J} / \mathrm{g}$, whereas, in case of FSP-M, the heat needed to denature the proteins was $190.07 \pm 13.09 \mathrm{~J} / \mathrm{g}$. The shift on the denaturation temperatures and heat flow can be related with the solvent used (HFIP), as well as with the processing technique, which can lead to a stabilization of the fish protein. After the first run, the samples were reheated and no peaks were observed during the second scan (data not shown). Therefore, these proteins had an irreversible denaturation. Furthermore, that increment on the denaturation temperature of FSP-M above the body temperature demonstrates their potential use for the development of wound dressing.

\subsection{Mechanical properties}

Three representative stress-strain curves for each batch of FSP$M$ are represented in Fig. 6. At low strain levels, the stress varies linearly with the strain in accordance with Hooks law. At higher strain levels, this variation becomes non-linear, indicating a shift from elastic to elastic-plastic behavior. FSP-M presented an average yield strength of $23.85 \pm 5.97 \mathrm{MPa}$, an average strain-to-failure of $2.33 \pm 0.70 \%$ and an average elastic modulus of $16.57 \pm 3.95 \mathrm{MPa}$ (at least 10 specimens were characterized for each condition).

The yield strength of the produced FSP-M is significantly higher than those of previously described solution-blown FSP/nylon 6 (50:50) fibrous meshes (0.52 MPa) [17], cast films from a FSP solution heated at $70^{\circ} \mathrm{C}(3-5.5 \mathrm{MPa})[15]$, a myofibrillar protein film

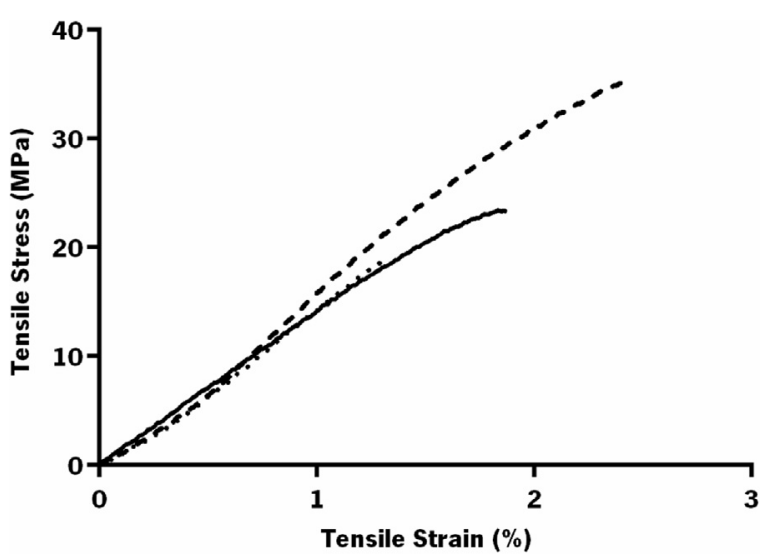

Fig. 6. Representative stress-strain curves of FSP-M from batch 1 (full line), 2 (dashed line), and 3 (dotted line).

(17 MPa) [12], and even chitosan membranes proposed for wound dressing (8.97 MPa) [43]. However, the herein described FSP-M had much lower elongation values than the previous films, 14.6, 40-75, 23 and $11.9 \%$, respectively. This suggests that the herein described FSP-M are more mechanically resistant and less stretchable than other protein-based films reported in the literature. The mechanical properties of the FSP-M are comfortable very interesting for applications in wound dressings.

\subsection{Swelling behavior and weight loss}

The swelling and weight loss behavior of FSP-M are important parameters of the characterization of the membranes intended for biomedical applications, since they are related with the stability of the materials in aqueous medium. We used DMEM in those studies to characterize the stability of the FSP-M during cell culture. In this way, we were able to analyze the effect of the cells over the stability of the membrane when it is exposed to the cells.

The swelling and weight loss behavior of FSP-M immersed in DMEM for $72 \mathrm{~h}$ is shown in Fig. 7A and B, respectively. In the beginning of the experiment, the FSP-M did not absorb ( $0 \%$ swelling) and did not lose weight ( $0 \%$ loss weight). In the first $12 \mathrm{~h}$ of incubation, the FSP-M absorbed 59\% of DMEM and lost $19 \%$ of its weight. After $24 \mathrm{~h}$, the swelling behavior is $73 \%$, losing $39 \%$ of weigh of FSP$\mathrm{M}$. After this time point, the swelling behavior started to decrease continuously, achieving $27 \%$ at $72 \mathrm{~h}$. On the other hand, the weight loss became constant, reaching a stable level of $\approx 43 \%$ until $72 \mathrm{~h}$.

The decrease in the swelling could be related with the loss of the internal structure of FSP-M, i.e. the weight loss. FSP-M can release low molecular weight protein compounds, existing at the
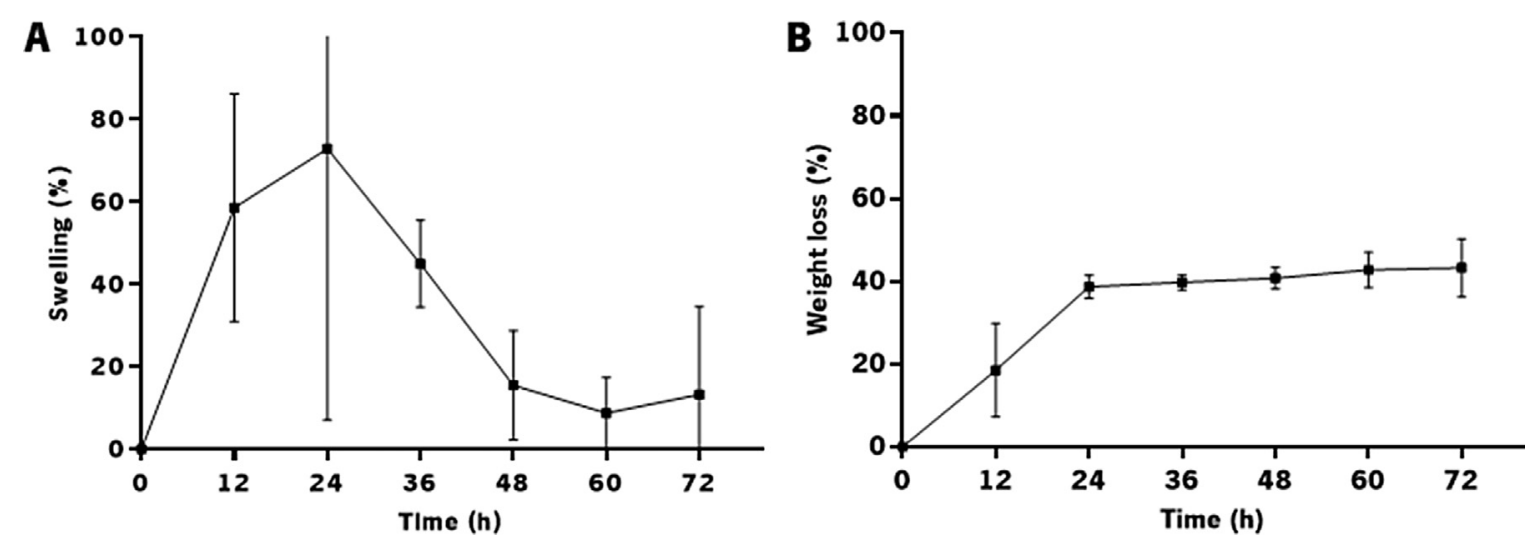

Fig. 7. Swelling behavior (A) and weigh lost (B) of FSP-M when immersed in DMEM for $72 \mathrm{~h}$. The results were expressed as mean values and standard deviation $(n=2)$. 
A
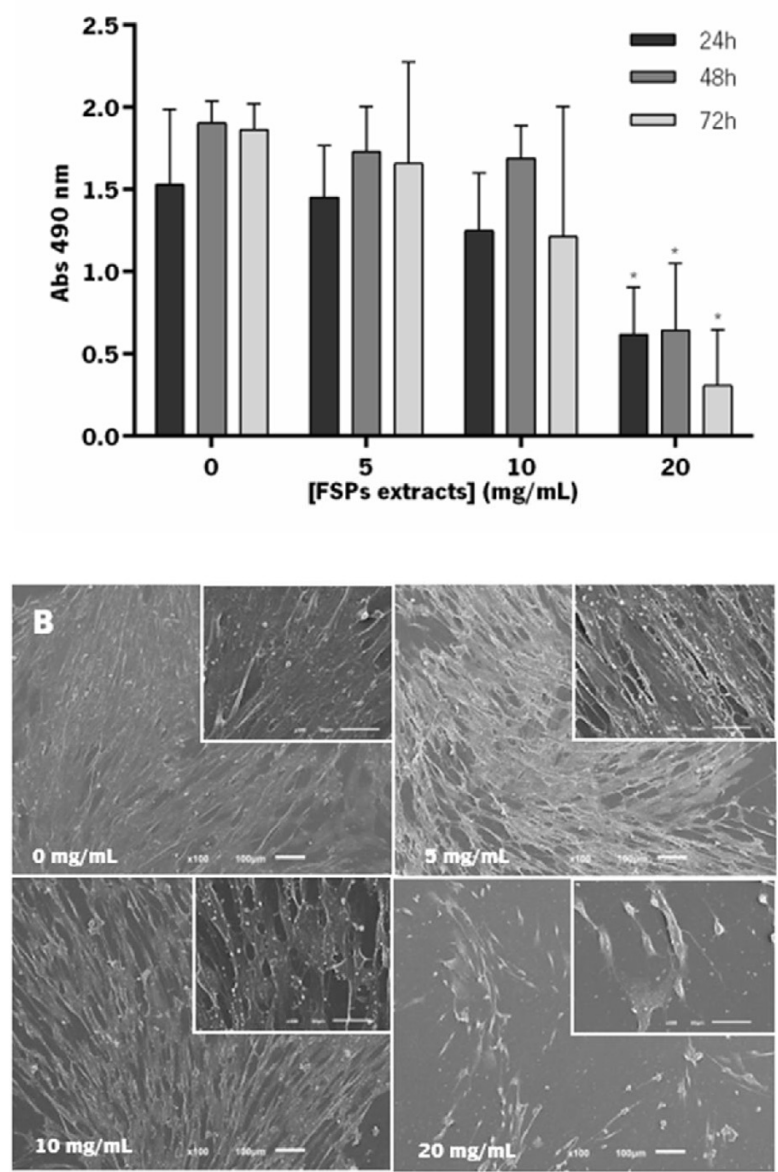

C

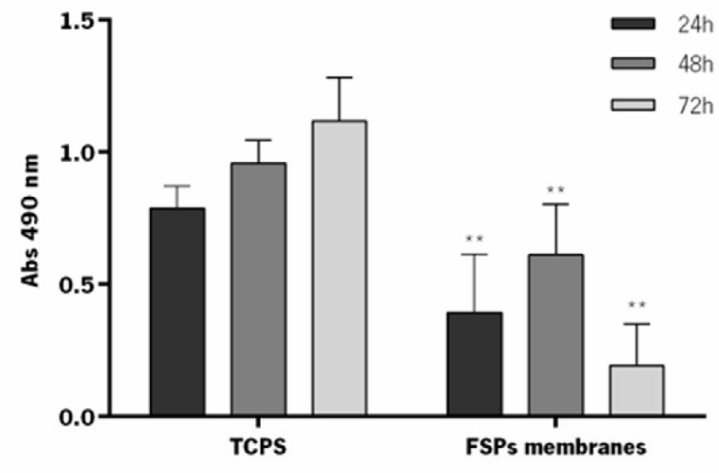

D

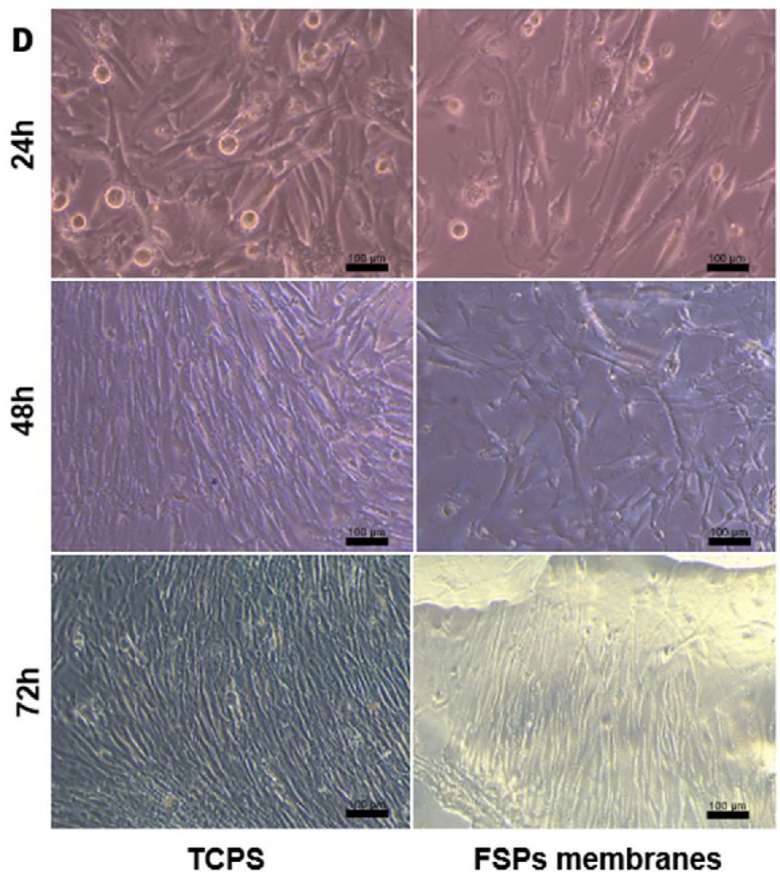

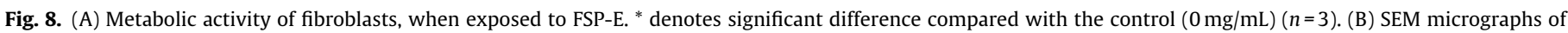

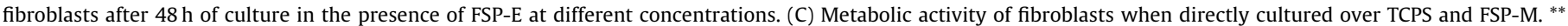
denotes significant difference compared with the control (TCPS) $(n=3)$. (D) Optical images of fibroblasts cultured directly over TCPS and FSP-M for 72 h.

membranes surface, which are easily detached upon contact with DMEM [18]. This can promote the release of the DMEM absorbed until the moment. However, the low molecular weight compounds were not enough to justify the high loss of swelling capacity. Thus, we hypothesize that those low molecular weight compounds may be hydrophilic, being capable to retain the DMEM entrapped in the FSP-M structure. When these compounds were released, the FSP-M loses the capacity to absorb the same amount of DMEM. However, despite the loss of structure, the FSP-M still retains 27\% of culture medium after $72 \mathrm{~h}$. This remaining absorption capacity maybe is related with the presence of insoluble proteins within the FSP-M. These results indicate that the FSP-M are insoluble in DMEM and can be used in the cellular studies to evaluate their cytocompatibility. It is important to highlight that no crosslinker agent was used to stabilize the FSP-M.

\subsection{Cytotoxicity of FSP-E}

The cytocompatibility of FSP-E, at concentrations ranging from 5 to $20 \mathrm{mg} / \mathrm{mL}$ was investigated with a human lung fibroblasts cell line (MRC-5). Fig. 8A shows the fibroblasts metabolic activity when exposed to FSP-E. For concentrations lower than $10 \mathrm{mg} / \mathrm{mL}$, no cytotoxicity was observed over the $72 \mathrm{~h}$ of culture. Cytotoxicity was observed for FSP-E concentration above $20 \mathrm{mg} / \mathrm{mL}$. The morphology of fibroblasts cultured with the FSP-E was analyzed by SEM (Fig. 8B). For concentrations lower than $10 \mathrm{mg} / \mathrm{mL}$, SEM micrographs showed higher amount of fibroblasts, with the typical elongated morphology and with pronounced philopodium. For higher concentrations, low number of fibroblasts were attached to the TCPS and their morphology becomes more rounded.

\subsection{Cytotoxicity of FSP-M}

The cytocompatibility of FSP-M was also investigated with human lung fibroblasts (MRC-5 cell line). Fig. 8C shows the metabolic activity of fibroblasts when directly cultured over TCPS and FSP-M. When the FSP-E were processed into the membrane format, only about $50 \%$ of fibroblasts adhered to the substrate, when compared with control condition (i.e. TCPS) after $24 \mathrm{~h}$ of culture. This was related with the hydrophobicity and negative charge sur- 
face (Fig. S1) of the FSP-M. However, the adhered fibroblasts present their typical elongated morphology and philopodium, as shown in Fig. 8D. After $48 \mathrm{~h}$ of culture, the fibroblasts attached to the FSP-M proliferate, showing a similar metabolic activity to the TCPS and their morphology remains the same as for $24 \mathrm{~h}$ (Fig. 8D). Therefore, the FSP-M were not cytotoxic for cells. If the FSP-M were cytotoxic, the adherent cells did not proliferate and, furthermore, a decrease of metabolic activity would be observed. After $72 \mathrm{~h}$ of culture, in spite of the fibroblasts showing an elongated morphology, their metabolic activity decreased drastically, because the integrity of FSP-M was lost. The fibroblasts produce enzymes that degrade the FSP-M, since they remain stable only in culture medium and not in the presence of cells. Indeed, as the FSP-M degrades faster in the presence of cells, it will be a good substrate for wound dressing application, where the loss integrity of the substrate may be value to the efficacy of the therapy.

\section{Conclusion}

FSP were successfully isolated from codfish by centrifugation, a method that was shown not to change their conformation. Our results show that different batches, from different individuals, yielded similar protein compositions. FSP-E and FSP-M presented similar physico-chemical properties. The denaturation temperature occurs above physiological temperature, thus not compromising the FSP stability in those conditions. FSP-M have superior mechanical properties as compared with other natural-based materials. FSP-E shown not having cytotoxicity for concentrations lower than $10 \mathrm{mg} / \mathrm{mL}$ and the fibroblasts attached and grew over the FSP-M. Based on these results, FSP can be considered a good candidate biomaterial in applications where the short duration in contact with cells will be an added value, such as in wound dressings and drug delivery systems.

\section{Acknowledgments}

This work was supported by the financial support from the Portuguese Foundation for Science and Technology (FCT) for the SV and SA PhD fellowship (PD/BD/135246/2017, SFRH/BD/112075/2015), ARF and EMF Post-Doctoral fellowships (SFRH/BPD/100760/2014, SFRH/BPD/96197/2013), Investigator Starting Grant of AM (IF/00376/2014), PATH (NORTE-08-5369FSE-000037), SPARTAN (PTDC/CTM-BIO/4388/2014), 3BsCOP $($ PTDC/BBB-ECT/3213/2014 - (POCI-01-0145-FEDER-016712)) and FROnTHERA (NORTE-01-0145-FEDER-0000232).

\section{Appendix A. Supplementary data}

Supplementary data associated with this article can be found, in the online version, at https://doi.org/10.1016/j.colsurfb.2018.04. 002.

\section{References}

[1] V. Venugopal, F. Shahidi, Food Rev. Int. 12 (1996) 175-197.

[2] J. Yongsawatdigul, P.A. Carvajal, T. Lanier, Surimi gelation chemistry, in: Surimi and Surimi Seafood, CRC Press, 2005, 2018, pp. 435-489.
[3] T. Nakagawa, S. Watabe, K. Hashimoto, Nippon Suisan Gakkaishi 54 (1988) 999-1004

[4] M. Toyohara, M. Murata, M. Ando, S. Kubota, M. Sakaguchi, H. Toyohara, J. Food Sci. 64 (1999) 804-807.

[5] S. Siriangkanakun, E.C.Y. Li-Chan, J. Yongsawadigul, Food Chem. 192 (2016) 1090-1097.

[6] S.T. Jiang, C.Y. Tsao, Y.T. Wang, C.S. Chen, J. Agric. Food Chem. 38 (1990) $1458-1463$.

[7] M.A. Audley, K.J. Shetty, J.E. Kinsella, J. Food Sci. 43 (1978) 1771-1775.

[8] R.H. Ilgner, A.E. Woods, Comp. Biochem. Physiol. Part B Comp. Biochem. 82 (1985) 433-440.

[9] H. Kishi, H. Nozawa, N. Seki, Nippon Suisan Gakkaishi 57 (1991) 1203-1210.

[10] M. Pazos, L. Méndez, J.M. Gallardo, S.P. Aubourg, Food Bioprocess Technol. 7 (2014) 2342-2353.

[11] N.F. Haard, B.K. Simpson, B.S. Pan, Sarcoplasmic proteins and other nitrogenous compounds, in: Z.E. Sikorski, B.S. Pan, F. Shahidi (Eds.), Seaf. Proteins, Springer, Boston, 1995, pp. 13-39.

[12] B. Cuq, C. Aymard, J.-L. Cuq, S. Guilbert, J. Food Sci. 60 (1995) 1369-1374.

[13] B. Cuq, N. Gontard, J.-L. Cuq, S. Guilbert, LWT - Food Sci. Technol. 29 (1996) 344-348.

[14] B. Cuq, N. Gontard, J.-L. Cuq, S. Guilbert, J. Food Sci. 61 (1996) 580-584.

[15] K.I. Iwata, S.H. Ishizaki, A.K. Handa, M.U. Tanaka, Fish. Sci. 66 (2000) 372-378.

[16] M. Tanaka, K. Iwata, R. Sanguandeekul, A. Handa, S. Ishizaki, Fish. Sci. 67 (2001) 346-351.

[17] S. Sett, K. Stephansen, A.L. Yarin, Polymer (Guildf.) 93 (2016) 78-87.

[18] K. Stephansen, I.S. Chronakis, F. Jessen, Colloids Surf. B. Biointerfaces 122 (2014) 158-165.

[19] K. Stephansen, M. Garcia-Diaz, F. Jessen, I.S. Chronakis, H.M. Nielsen, Int. J. Pharm. 495 (2015) 58-66.

[20] K. Stephansen, M. Mattebjerg, J. Wattjes, A. Milisavljevic, F. Jessen, K. Qvortrup, F.M. Goycoolea, I.S. Chronakis, Int. J. Biol. Macromol. 76 (2015) $146-152$.

[21] Y.M. Sahin, S. Su, B. Ozbek, S. Yücel, O. Pinar, D. Kazan, F.N. Oktar, N. Ekren, O. Gunduz, J. Food Eng. 222 (2018) 54-62.

[22] S. Rethinam, P. Nivedita, T. Hemalatha, S. Weslen Vedakumari, T.P. Sastry, Int. J. Artif. Organs. 39 (2016) 509-517.

[23] R. Singh, M.P. Chacharkar, A.K. Mathur, Int. Wound J. 5 (2008) 665-673.

[24] S. Aoyagi, H. Onishi, Y. Machida, Int. J. Pharm. 330 (2007) 138-145.

[25] E.D. Pinho, A. Martins, J.V. Araujo, R.L. Reis, N.M. Neves, Acta Biomater. 5 (2009) 1104-1114.

[26] W. Li, J. Zhou, Y. Xu, Biomed. Rep. 3 (2015) 617-620.

[27] P. Tadpitchayangkoon, J.W. Park, J. Yongsawatdigul, Food Chem. 121 (2010) 1046-1052.

[28] D. Skipnes, I. Van der Plancken, A. Van Loey, M.E. Hendrickx, J. Food Eng. 85 (2008) 51-58.

[29] K.A. Thorarinsdottir, S. Arason, M. Geirsdottir, S.G. Bogason, K. Kristbergsson, Food Chem. 77 (2002) 377-385.

[30] T. Nakagawa, S. Watabe, K. Hashimoto, Nippon Suisan Gakkaishi 54 (1988) 993-998.

[31] K. Morioka, T. Nishimura, A. Obatake, Y. Shimizu, Fish. Sci. 63 (1997) 111-114.

[32] B.-O. Hemung, K.B. Chin, LWT - Food Sci. Technol. 53 (2013) 184-190.

[33] E.L. LeBlanc, R.J. LeBlanc, J. Food Sci. 54 (1989) 827-834.

[34] P. Arenberger, P. Engels, M. Arenbergerova, S. Gkalpakiotis, F.J. García Luna Martínez, A. Villarreal Anaya, L. Jimenez Fernandez, GMS Krankenhhyg Interdiszip 6 (2011), Doc05.

[35] U. w. e. Schlattner, N. Möckli, O. Speer, S. Werner, T. Wallimann, J. Invest. Dermatol. 118 (2002) 416-423.

[36] S.M. McCarty, S.L. Percival, Adv. Wound Care 2 (2013) 438-447.

[37] A.J. Miles, B.A. Wallace, Circular dichroism spectroscopy for protein characterization: biopharmaceutical applications, in: D.J. Houde, S.A. Berkowitz (Eds.), Biophys. Charact. Proteins Dev. Biopharm., Elsevier, Amsterdam, 2015, pp. 109-137.

[38] G. Villamonte, L. Pottier, M. de Lamballerie, Eur. Food Res. Technol. 242 (2016) 667-675.

[39] L. Stevens, R. Townend, S.N. Timasheff, G.D. Fasman, J. Potter, Biochemistry 7 (1968) $3717-3720$

[40] G.D. Fasman, M. Landsberg. M. Buchwald, Can. J. Chem. 43 (1965) 1588-1598.

[41] S.-W. Ha, T. Asakura, R. Kishore, Biomacromolecules 7 (2006) 18-23.

[42] E.S. Monterrey-Quintero, P.J. do, A. Sobral, Pesqui. Agropecuária Bras. 35 (2000) 179-189.

[43] D.J.I., F.L., Y. Yulizar, IOP Conf. Ser. Mater. Sci. Eng. 202 (2017) 12020. 